\title{
TRANSFORMASI PENDIDIKAN ISLAM ANAK DI SEKOLAH DALAM PERSPEKTIF PSIKOLOGI DI ERA REVOLUSI INDUSTRI 4.0
}

\author{
Khoirotus Silfiyah \\ silfiyahsania@gmail.com \\ UNU Sunan Giri Bojonegoro
}

\begin{abstract}
This research aims to find out the transformation of school and education in the perspective of psychology in era 4.0. This research uses the method of reseacrh library approach or librarian study. That is, in this study using books, previous research journals, articles in the form of magazines or newspapers, and other scientific writings. The results show that teachers and children are required to be ready in the face of the transformation of education and school that is happening now. However, the fact that the impact of learning transformation that all uses technology, especially gadgets psychological perspective actually makes children easily experience emotions that are less stable, concentration decreases and frequent tantrums. Seeing these conditions, it takes good synergy between teachers, parents, and the community to participate in order to be able to give birth to an independent, intelligent generation and able to meet a better future.
\end{abstract}

Keywords: educational and school transformation, psychology and era 4.0

\begin{abstract}
Abstrak: Penelitian ini bertujuan untuk mengetahui transformasi sekolah dan pendidikan dalam perspektif psikologi di era 4.0. Penelitian ini menggunakan metode pendekatan library reseacrh atau studi kepustakaan. Artinya, pada penelitian ini menggunakan rujakan buku-buku, jurnal penelitian sebelumnya, artikel- artikel berupa majalah atau surat kabar, dan tulisan ilmiah lainnya. Hasil penelitian menunjukkan bahwa guru dan anak dituntut untuk siap dalam menghadapi transformasi pendidikan dan sekolah yang terjadi kini. Namun, faktanya dampak transformasi pembelajaran yang serba menggunakan teknologi, khususnya gadget perspektif psikologi justru membuat anak mudah mengalami emosi yang kurang stabil, konsentrasi menurun dan sering tantrum. Melihat kondisi tersebut, dibutuhkan sinergitas yang baik antara guru, orang tua, dan masyarakat untuk turut berpartisipasi agar mampu melahirkan generasi mandiri, cerdas serta mampu menyongsong masa depan yang lebih baik.
\end{abstract}

Kata Kunci: transformasi pendidikan dan sekolah, psikologi dan era 4.0

\section{Pendahuluan}

Saat ini Indonesia mengalami perkembangan yang sangat pesat dalam bidang teknologi. Perkembangan teknologi tersebut ditandai dengan adanya mobile dan internet yang merajalela di setiap kalangan. Berdasarkan penuturan Menteri Riset, Tekhnologi dan Pendidikan Tinggi Mohamad Nasir, bahwa negara Indonesia memiliki potensi yang tinggi dalam menghadapi revolusi Industri 4.0. Adapun perubahan yang terjadi akibat perkembangan teknologi ini tentunya memberikan dampak positif maupun negatif dalam segala bidang politik, ekonomi, sosial budaya, termasuk pendidikan. 
Istilah lain dari era 4.0 adalah era cyber. Artinya, era tanpa batas, sekat waktu dan ruang. Era terciptanya mesin pintar, robot otonom, bahkan Artificial Intelegent (AI). Generasi era 4.0 juga disebut generasi internet, yang mana mereka bisa berinteraksi dengan siapapun, kapanpun, tanpa adanya sekat waktu.

Dunia pendidikan era 4.0 memanfaatkan tekhnologi sebagai media pembelajaran. Hal ini dikarenakan semua masyarakat dari semua golongan memiliki smartphone maupun laptop. Individu dapat mendownload berbagai platform belajar seperti Google Classroom, Zoom Meeting, Google Meet dan platform lainnya, sehingga kegiatan belajar dan mengajar dapat dilakukan jarak jauh, kapan pun dan di manapun individu berada. Pembelajaran dapat berjalan dengan lancar hanya dengan menggunakan gadget. Hal ini dikarenakan gadget mempunyai berbagai fitur dan aplikasi yang menarik, bervariasi, sehingga menjadikan pengguna lebih interaktif dan menambah daya tarik.

Penjelasan di atas menunjukkan bahwa, dalam dunia pendidikan mengalami transformasi yang luar biasa. Pembelajaran dapat dilakukan dengan fleksibel melalui platform yang bervariasi. Berdasakan penelitian yang dilakukan oleh Rinawati mengemukan bahwa peran transformasi pendidikan dimaksudkan menghasilkan individu yang siap menghadapi tantangan global. Adapun salah satu cara yang digunakan untuk menghadapi tantangan global dalam dunia pendidikan yaitu dengan meningkatkan peran guru yang dapat menyesuaikan kondisi, sehingga pendidikan tidak mengalami ketertinggalan dan bertahan menghadapi dampak negatif globalisasi. Hal tersebut menunjukkan bahwa dalam transformasi pendidikan di era globalisasi memiliki dampak negatif maupun positif.

Selain itu, transformasi digital yang dimaksud tidak hanya menggunakan teknologi dalam proses pembelajaran. Akan tetapi, peserta didik diarahkan untuk mampu berpikir secara tekhnologi computational thinking (cara berpikir komputasi). Artinya, peserta didik dapat memiliki kemampuan dalam menyelesaikan persoalan dengan teknik komputer.

Berdasarkan penjabaran di atas dapat disimpulkan bahwa dalam pendidikan dan sekolah mengalami trasnformasi yang sangat mencolok, dalam hal ini adalah media pembelajaran. Adapun salah satu media pembelajaran yang digunakan di era 4.0 yakni gadget. Adanya gadget memudahkan anak dalam mencari berbagai macam informasi tentang materi pembelajaran. Menurut D. Taspcott, dampak positif gadget juga hampir seluruhnya dapat dirasakan oleh generasi Z, yakni generasi yang lahir pada kisaran tahun 1998 hingga 2009. Generasi ini dapat mengakses informasi yang dibutuhkan kapan pun dan di mana pun. Tanpa batas waktu. Selain itu, gadget juga memudahkan anak dalam berkomunikasi dengan orang lain. 
Kendati demikian, gadget juga memiliki dampak negatif, yakni membuat anak kecanduan. Menurut Sari dan Mitsalia, kategori kecanduan yakni jika anak menggunakan gadget melebihi 2 jam per hari. Atau bahkan 3 kali dalam sehari dengan durasi waktu 30- 75 menit. Ini sudah termasuk kategori intensitas tinggi. Dengan demikian, kecanduan gadget dapat menghambat perkembangan interaksi sosial anak. Hal tersebut menjadikan anak malas untuk belajar, baik belajar secara mandiri maupun bersama teman- temannya. Apalagi didukung dengan hasil penelitian, bahwa anak usia 910 tahun $75 \%$ yang menggunakan gadget sebelum tidur, akan mengalami penurunan pada prestasi belajarnya.

Kerap kali, kita juga menjumpai anak- anak yang sering lupa waktu karena kecanduan gadget. Faktanya, saat anak sedang makan, bermain, bersantai atau aktivitas apapun, rasanya gadget sulit sekali lepas dalam genggaman. Anak lebih sering berselancar di dunia maya daripada berinteraksi dengan orang- orang di sekitarnya. Padahal, menurut Maslow seorang pakar psikologi menyatakan, bahwa salah satu kebutuhan pokok manusia yakni kebutuhan sosial, seperti dicintai, mampu bekerjasama, diakui sebagai kelompok.

Berdasarkan fakta di atas, jika ditinjau dari perspektif psikologi, tentu dampak dari transformasi pendidikan dan sekolah ini luar biasa. Adanya dampak positif maupun negatif tentu turut berpartisipasi dalam transformasi ini. Penelitian ini bertujuan untuk mengetahui bagaimana transformasi yang dialami oleh pendidikan dan sekolah dalam perspektif psikologi. Artikel ini ditulis dengan harapan untuk bisa menganilisis perilaku yang harus dikuasai anak-anak saat ini untuk masa depannya bukan sekedar pada pemenuhan kebutuhan hidup secara materi tetapi juga ketentraman dalam hidup bermasyarakat.

Penelitian ini menggunakan pendekatan library reseacrh atau studi kepustakaan. Artinya, pada penelitian ini menggunakan rujukan buku-buku, jurnal penelitian sebelumnya, artikel- artikel yang relevan dalam majalah atau surat kabar, dan tulisan ilmiah lainnya. Artikel ini ingin menguraikan perkembangan Pendidikan yang ada di Indonesia dalam kacamata psikologi sebagai sebuah pandangan yang melihat fenomena Pendidikan dan sekolah saat ini ditengah perkembangan teknologi yang begitu cepat berlari

\section{Transformasi pendidikan anak di sekolah dalam persepektif Psikologi analitik}

Adapun transformasi merupakan suatu peralihan atau proses penciptaan sesuatu yang baru. ${ }^{1}$ Bidang pendidikan merupakan alat transformasi yang luar biasa jika dikembangkan secara maksimal. Hal ini karena bidang- bidang yang lain, seperti ekonomi, sosial budaya, politik dan

\footnotetext{
${ }^{1}$ Anita Rinawati, 'Transformasi Pendidikan Untuk Menghadapi Globalisasi', 3.1 (2015). 
sebagainya akan turut berkembang pesat jika transformasi pendidikan ditanggapi dengan sigap dan cepat. Namun, pada faktanya, pendidikan di Indonesia masih tertinggal jika dibandingkan dengan negara- negara lain. ${ }^{2}$

Dalam pandangan masyarakat saat ini pendidikan lebih diarahkan pada pemenuhan ekonomi peserta didik dimasa mendatang kelak saat mereka sudah dewasa untuk mendapatkan kesejahteraan. Nyatanya saat ini, perekonomian global abad ke-21 dikendalikan oleh jaringan teknologi informasi, di mana semua transaksi dilakukan secara online, investasi dan pasar modal dilakukan tanpa melihat gejolak kehidupan nyata, kecuali dengan cara melihat angka-angka di monitor. Angka-angka itu berubah dari menit ke menit, seiring dengan gejolak yang terjadi dalam ekonomi perdagangan, politik, sosial dan isu-isu sentsitif lain. Dalam kondisi pasar global semacam ini, maka apa yang terjadi di satu negara, pengaruhnya akan terasa di negara lain

Saat ini, pendidikan menjadi semakin penting untuk menjamin peserta didik memiliki keterampilan belajar dan berinovasi, keterampilan menggunakan teknologi dan media informasi, serta dapat bekerja, dan bertahan dengan menggunakan keterampilan untuk hidup (life skills). Saat ini, informasi yang tersedia dimana saja dan dapat diakses kapan saja; mobilisasi yang semakin cepat; otomasi yang menggantikan pekerjaan-pekerjaan rutin; komunikasi yang dapat dilakukan dari mana saja dan kemana saja dan oleh siapa saja.

Dalam dunia pendidikan sudah dirasakan adanya pergeseran, dan bahkan perubahan yang bersifat mendasar pada tataran filsafat, arah serta tujuannya. Tidaklah berlebihan bila dikatakan kemajuan ilmu tersebut dipicu oleh lahirnya sains dan teknologi komputer. Dengan piranti mana kemajuan sains dan teknologi terutama dalam bidangcognitive science, bio-molecular, information technology dan nano-science kemudian menjadi kelompok ilmu pengetahuan yang mencirikan abad ke-21. Salah satu ciri yang paling menonjol pada

Transformasi pendidikan dan sekolah, terutama yang dialami oleh anak yakni terlalu lama dalam menatap layar gadget. Bahkan, gadget dan internet merupakan kebutuhan pokok yang tak terbantahkan. Akibatnya, anak menjadi kecanduan gadget, sehingga hal tersebut dapat menghambat perkembangan anak. ${ }^{3}$

Salah satu penghambat yang dimaksud yakni pada sisi interpersonal anak. Hal ini mengakibatkan anak lebih cenderung bergantung pada gadget daripada berpikir dan merenungi suatu persolan secara mandiri. Perilaku tersebut memiliki dampak pada prestasi belajar anak. ${ }^{4}$ Selain menghambat pada perkembangan anak, kecanduan gadget juga dapat menimbulkan mata anak

\footnotetext{
${ }^{2}$ No and Rinawati.

3 Fitra Mayenti, "Dampak Penggunaan Gadget Terhadap Perkembangan Anak Usia Dini di PAUD dan TK Taruna Islam Pekanbaru," dalam Jurnal Photon, no.1 Oktober 2018, hlm.209

${ }^{4}$ Wulan Patria Saroinsong, "Gadget Usage Inbibited Interpersonal Interpersonal Intelligence Of Children On Ages 6-8 Years Old. Publications, Scientific Technology, Educational, 2016. Hlm.775-781.
} 
menjadi kabur. Hal ini disebabkan oleh pancaran radiasi emisi pada gadget. ${ }^{5}$ Anak juga akan mengalami emosi yang kurang stabil, konsentrasi menurun dan sering tantrum.

Tantrum merupakan kondisi pada anak yang mudah sekali dalam meluapkan emosi. Bisa dikatakan anak menjadi mudah marah dan mudah frustasi akan suatu hal. ${ }^{6}$ Kecanduan gadget juga menyebabkan anak kurang komunikasi, serta mengalami penurunan pada psikomotorik, karena tubuh anak kurang melakukan pergerakan. Dengan demikian, peran orang tua, pihak sekolah, serta masyarakat memiliki pengaruh besar terhadap perkembangan anak dalam menghadapi transformasi sekolah dan pendidikan di era 4.0.

Mengacu pada Peraturan Menteri Pendidikan RI No.22-24 Tahun 2006, masing- masing sekolah diberikan kewenangan untuk menyusun kurikulum, tentu dengan melibatkan seluruh pihak sekolah dan stake holder. Kurikulum dapat dirancang sesuai dengan kebutuhan. Melalui hal ini akan memudahkan guru maupun anak untuk berinovasi dan memahami materi pelajaran secara holistik. Inovasi dan kreatifitas guru dalam mengelola pembelajaran menjadi kunci dalam transformasi pendidikan dan sekolah.

Adapun peran dari pihak sekolah, yakni selalu bersinergi dengan orang tua dalam membantu tumbuh kembang anak agar optimal. Pendidik hendaknya selalu mengkomunikasikan terkait perkembangan anak, misalnya mengalami kesulitan dalam belajar. Hal ini dikarenakan pendidik dianggap sebagai ujung tombak keberhasilan anak dalam proses belajar, sehingga diharapkan ada solusi alternatif yang dapat membantu memecahkan masalah yang dihadapi oleh anak.

Selain itu, orang tua diharapkan mampu meminimalisir penggunaan gadget pada anak. Misalnya, anak dibatasi bermain gadget hanya 20 menit per hari. Selain itu, orang tua dapat memblokir situs-situs dewasa yang tidak sesuai dengan umur anak. Hal ini dilakukan sebagai upaya agar anak tidak selalu bergantung pada gadget dan perilaku amoral. Memberikan nasihat kepada anak tanpa memarahi ataupun memaksa merupakan langkah bijak yang harus ditempuh oleh orang tua. Selain itu, orang tua hendaknya menjadi role model yang baik bagi anak. Misalnya, ketika sedang bermain bersama anak, hendaknya orang tua tidak sibuk sendiri dengan gadget miliknya.

\footnotetext{
${ }^{5}$ Kumparan, "Dampak Gadget Terhadap Anak dan Cara Mengatasinya," (Online), https://kumparan.com/babyologist/dampak-gadget-terhadap-anak-dan-cara-mengatasinya-1rMCBDINzyO/full diakses 11 April 2021.

"Kumparan, "Psikolog: Gadget Bisa Bikin Anak Tantrum, Ini Alasannya," (Online) https://kumparan.com/kumparanmom/psikolog-gadget-bisa-bikin-anak-tantrum-ini-alasannya$1543815817356330401 /$ full diakses 11 April 2021.
} 


\section{Arah transformasi pendidikan Islam dalam perspektif psikologi di era 4.0}

Arah terang pendidikan Islam yang menjadi kunci transformasi pendidikan di Indonesia yang masyarakatnya mayoritas muslim dan merupakan negara berpenduduk muslim terbesar di dunia dituntut untuk mampu memberikan kontribusi yang signifikan. Ia menjadi prioritas utama untuk dilaksanakan sebab sampai saat ini masyarakat muslim sangat terbelakang di bidang pendidikan. Dengan demikian salah satu target yang harus diusahakan semaksimal mungkin adalah revitalisasi pelaksanaan pendidikan bagi umat Islam melalui proses yang sesuai dengan nilai-nilai dan motif ajaran Islam sehingga tidak salah arah dengan pelaksanaan pendidikan ala Barat. Untuk menyikapinya diperlukan penyusunan sistem pendidikan yang berakar pada nilai-nilai, prinsipprinsip dan tujuan-tujuan Islam. ${ }^{7}$

Psikologi dan pendidikan Islam memiliki peran dalam dunia pendidikan baik itu dalam belajar dan pembelajaran. Pengetahuan tentang psikologi sangat diperlukan oleh orang tua/pendidik dalam memahami karakteristik, kognitif, afektif dan psikomotorik, karena secara integral pemahaman psikologis peserta didik oleh pihak pendidik memiliki kontribusi yang sangat berarti dalam proses pendidikan peserta didik sesuai dengan sikap, minat, motivasi, aspirasi, dan kebutuhan peserta didik, sehingga proses pembelajaran di kelas dapat berlangsung secara optimal dan maksimal. Lebih dari itu psikologi diperlukan dalam menganalisis perilaku anak-anak kita kelak, kecenderungan apa yang mungkin timbul dan berefek negative bagi perilaku anak dimasa depan.

Pendidikan Islam adalah sistem pendidikan yang dapat memberikan kemampuan seseorang untuk memimpin kehidupannya, sesuai dengan cita-cita Islam, karena nilai-nilai Islam telah menjiwai dan mewarnai corak kepribadiannya. Pendidikan Islam bila dilihat dari segi kehidupan kultural umat manusia tidak lain adalah merupakan salah satu alat pembudayaan (enkulturasi) masyarakat manusia itu sendiri. Pendidikan Islam adalah proses membimbing dan mengarahkan pertumbuhan serta perkembangan anak didik agar menjadi manusia dewasa. ${ }^{8}$

Selanjutnya, peran masyarakat. Anak- anak mengimplementasikan ilmu yang telah didapat, baik dari orang tua dan sekolah di lingkup masyarakat. Sifatnya aplikatif, bukan teoritis. Artinya, anak- anak berperilaku sesuai dengan ilmu yang telah mereka peroleh. Dengan demikian, hendaknya orang tua selalu mendorong anak untuk berada dalam lingkungan yang baik. Perilaku yang amat penting untuk ditanamkan sejak dini adalah perilaku saling menghargai dan toleran terhadap perbedaan. ${ }^{9}$

\footnotetext{
7 Suprayetno, "Modernisasi Sistem Pendidikan Pesantren sebagai Kebutuhan Masyarakat", dalam Dody S. Truna dan Ismatu Ropi, Pranata Islam di Indonesia: Pergulatan Sosial, Politik, Hukum, dan Pendidikan, cet.I, (Ciputat: Logos Wacana Ilmu, 2002), hal. 273

${ }^{8}$ M. Arifin, Kapita selekta Pendidikan (Islam dan Umum), (Jakarta: Bumi Aksara, 2000), hal. 10-16

9 Abidin, Achmad Anwar, Model Of Implementing Islamic Education V alues In Strengthening Tolerant Behavior In Plural Societies, Jurnal Pendidikan Multikultural, Volume 5, Nomor 2 (2021)
} 
Pada saat ini teknologi di Era 4.0 tidak sepenuhnya membawa dampak positif bagi sekolah dan pendidikan. Akan tetapi, tidak sepenuhnya juga membawa dampak negatif. Semua tergantung pada sikap kita dalam menghadapi era yang serba canggih ini. Terdapat dua pilihan, yakni memanfaatkan era 4.0 dengan baik atau justru kita yang dimanfaatkan teknologi sehingga dapat terjerumus ke dalam hal- hal yang kurang baik. Perkembangan teknologi 4.0 sudah seharusnya diimbangi pula dengan kecerdasan spiritual dan emosional. Sebagai orang tua, tenaga pendidik maupun masyarakat tentu harus saling bersinergi agar dapat membantu tumbuh kembang anak secara optimal. Diharapkan, dengan melakukan upaya demikian, transformasi sekolah dan pendidikan di era 4.0 dapat membentuk generasi yang cerdas, berdaya saing dan bertakwa kepada Tuhan Yang Maha Esa. Karena adanya transformasi pendidikan ini diharapkan mampu melahirkan generasi yang mampu untuk mandiri, menjalani kehidupan yang bermakna serta mampu dalam menjalankan kehidupan dengan baik. ${ }^{10}$

\section{Kesimpulan}

Transformasi pendidikan dan sekolah mengharuskan pemanfaatan teknologi, salah satunya berupa gadget. Adanya gadget sangat mempengaruhi sisi interpersonal anak. Apalagi jika sampai pada tahap kecanduan gadget, sehingga anak menjadi mudah marah dan frustasi akan suatu hal. Menanggapi hal tersebut, dibutuhkan sinergitas antara guru, orang tua, hingga masyarakat untuk turut berpartisipasi dalam membantu tumbuh kembang anak agar optimal. Penggunaan teknologi yang cerdas dan bijak, diharapkan mampu untuk menghadapi transformasi pendidikan dan sekolah yang serba digitalisasi, sehingga terwujudnya generasi mandiri, cerdas dan berperilaku saling menghargai dan toleran terhadap perbedaan yang nantinya mampu menyongsong masa depan yang lebih baik.

\section{Daftar Pustaka}

Abidin, Achmad Anwar, Model Of Implementing Islamic Education Values In Strengthening Tolerant Behavior In Plural Societies, Jurnal Pendidikan Multikultural, Volume 5, Nomor 2 (2021) DOI: http://dx.doi.org/10.33474/multikultural.v5i2.12318

Adun, Priyanto. Jurnal Pendidikan Agama Islam dalam Era Revolusi Industri 4.0. Vol. 6 No.2. 2020. IAIN Purwokerto

\footnotetext{
${ }^{10}$ Etistika Yuni Wijaya and others, 'Transformasi Pendidikan Abad 21 Sebagai Tuntutan Pengembangan Sumber Daya Manusia Di Era Global', 1 (2016), 263-78.
} 
Bhennita Sukmawati, "Pengaruh Gadget Terhadap Perkembangan Bicara Anak Usia 3 Tahun di TK Buah Hati Kita," dalam Jurnal Garuda, no. 1 (Juli 2019), hlm.53.

Dewanto Samodro, "Dampak Negatif Gadget Bagi Anak, Psikolog: Anak Malas Belajar," (Online), https://www.liputan6.com/health/read/3235563/dampak-negatif-gadget-bagianak-psikolog-anak-malas-belajar diakses 11 April 2021.

Etistika Yuni Wijaya and others, 'Transformasi Pendidikan Abad 21 Sebagai Tuntutan Pengembangan Sumber Daya Manusia Di Era Global', 1 (2016), 263-78.

Fitra Mayenti, "Dampak Penggunaan Gadget Terhadap Perkembangan Anak Usia Dini di PAUD dan TK Taruna Islam Pekanbaru," dalam Jurnal Photon, no.1 Oktober 2018, hlm.209

Https://www.kompasiana.com/poltakbutarbutar8687/5e2eab1bd541df18de53eae2/transformasi -digital-dalam-dunia-pendidikan

Kumparan, "Dampak Gadget Terhadap Anak dan Cara Mengatasinya," (Online), https://kumparan.com/babyologist/dampak-gadget-terhadap-anak-dan-caramengatasinya-1rMCBDINzyO/full diakses 11 April 2021.

Kumparan, "Psikolog: Gadget Bisa Bikin Anak Tantrum, Ini Alasannya," (Online) https:/ kumparan.com/kumparanmom/psikolog-gadget-bisa-bikin-anak-tantrum-inialasannya-1543815817356330401/full diakses 11 April 2021.

M. Ngalim Purwanto, Psikologi Pendidikan, (Bandung: PT. Remaja Rosdakarya, 2013), hlm.78.

R. Willya Achmad W, dkk, "Potret Generasi Milenial Pada Era Revolusi Industri 4.0," dalam Jurnal Pekerjaan Sosial, no,2 (Desember 2019), hlm.190

Anita Rinawati, 'Transformasi Pendidikan Untuk Menghadapi Globalisasi', 3.1 (2015).

Wulan Patria Saroinsong, "Gadget Usage Inhibited Interpersonal Interpersonal Intelligence Of Children On Ages 6-8 Years Old. Publications, Scientific Technology, Educational, 2016. Hlm.775-781. 